\title{
Glaciar Jorge Montt (Chilean Patagonia) dynamics derived from photos obtained by fixed cameras and satellite image feature tracking
}

\author{
Andrés RIVERA, ${ }^{1,2}$ Javier CORRIPIO, ${ }^{3}$ Claudio BRAVO, ${ }^{1}$ Sebastián CISTERNAS ${ }^{1}$ \\ ${ }^{1}$ Centro de Estudios Científicos (CECS), Valdivia, Chile \\ E-mail: arivera@cecs.cl \\ ${ }^{2}$ Departamento de Geografía, Universidad de Chile, Santiago, Chile \\ ${ }^{3}$ meteoexploration.com
}

\begin{abstract}
Tidewater calving glaciers can undergo large fluctuations not necessarily in direct response to climate, but rather owing to complex ice-water interactions at the glacier termini. One example of this process in Chilean Patagonia is Glaciar Jorge Montt, where two cameras were installed in February 2010, collecting up to four glacier photographs per day, until they were recovered on 22 January 2011. Ice velocities were derived from feature tracking of the geo-referenced photos, yielding a mean value of $13 \pm 4 \mathrm{~m} \mathrm{~d}^{-1}$ for the whole lower part of the glacier. These velocities were compared to satelliteimagery-derived feature tracking obtained in February 2010, resulting in similar values. During the operational period of the cameras, the glacier continued to retreat $(1 \mathrm{~km})$, experiencing one of the highest calving fluxes ever recorded in Patagonia $\left(2.4 \mathrm{~km}^{3} \mathrm{a}^{-1}\right)$. Comparison with previous data also revealed ice acceleration in recent years. These very high velocities are clearly a response to enhanced glacier calving activity into a deep water fjord.
\end{abstract}

\section{INTRODUCTION}

The Patagonian icefields have been shrinking at high rates in the last 50 years, compared to the area losses experienced since the Little Ice Age, contributing significantly to sealevel rise (Glasser and others, 2011). The Southern Patagonia Icefield (SPI; Campo de Hielo Sur), in the Southern Andes of Chile and Argentina, is the largest temperate ice field in the Southern Hemisphere, with 48 main basins and nearly $13000 \mathrm{~km}^{2}$ of ice (Aniya and others, 1996). Most of its glaciers are calving into lakes or fjords, with the majority of them, including Glaciar Jorge Montt, experiencing strong frontal retreat and thinning at very high rates during recent years (Aniya and others, 1997; Rignot and others, 2003). Among the few exceptions are Glaciar Moreno which is stable and Glaciar Pío XI which has advanced (Masiokas and others, 2009).

Glaciar Jorge Montt $\left(48^{\circ} 19^{\prime} \mathrm{S}, 7^{\circ} 29^{\prime} \mathrm{W}\right.$; ice basin area $500 \mathrm{~km}^{2}$ in 2011) is one of the main tidewater calving glaciers of the SPI. It flows north from the local ice divide ( 1600 ma.s.l.) located within one of the main plateaus of the SPI, to calve into an unnamed fjord that opened as a result of the glacier retreat experienced since 1898 (Steffen, 1910), yielding a total retreat of $19.5 \mathrm{~km}$ until 2011 (Fig. 1). Very little is known about how glacier velocities are reacting to these significant changes. Very few ice velocities have been measured in the SPI, resulting in a wide rate range, from a few meters per day at Glaciar Moreno with some seasonality (Stuefer and others, 2007; Ciappa and others, 2010; Sugiyama and others, 2011), to a mean ice velocity near the front of Glaciar Pío XI of $20 \mathrm{~m} \mathrm{~d}^{-1}$, with maximum values of $50 \mathrm{~m} \mathrm{~d}^{-1}$, when surging behaviour was suggested (Rivera and others, 1997). One of the glaciers with more direct ice velocity measurements is Glaciar San Rafael, Northern Patagonia Icefield (NPI; Campo de Hielo Norte), where up to $17-20 \mathrm{~m} \mathrm{~d}^{-1}$ was detected near the tidewater calving glacier front (Naruse, 1985, 1987; Kondo and Yamada, 1988;
Warren and others, 1995; Rignot and others, 1996a,b). Another SPI glacier with direct ice velocity measurements is Glaciar Tyndall, where a maximum of $1.9 \mathrm{~m} \mathrm{~d}^{-1}$ was measured in 1985 near the medial moraine (Kadota and others, 1992). Most of these ice velocities were obtained by measuring stakes, seracs, erratic blocks or other features on top of the glacier, by theodolite. More recently, satellite images (Floricioiu and others, 2009) and continuous GPS measurements (Sugiyama and others, 2011) have been used. Terrestrial oblique photography has been applied to at least one glacier in Patagonia (Hashimoto and others, 2009, 2011).

The first published velocities from Glaciar Jorge Montt were from Enomoto and Abe (1983) who measured $240 \mathrm{ma}^{-1}$ at a western non-calving tongue. Using speckle tracking from RADARSAT-1 images collected in SeptemberNovember 2004, E. Rignot (personal communication, 2011) obtained values of $9-10 \mathrm{~m} \mathrm{~d}^{-1} 3 \mathrm{~km}$ upstream of the glacier front. In this paper, these values are compared to ice velocities derived from fixed cameras installed near the glacier edge, pointing toward the lower tongue of Glaciar Jorge Montt and operating almost continuously between 9 February 2010 and 15 January 2011. These results are also compared to feature-tracking ice velocities derived from Advanced Spaceborne Thermal Emission and Reflection Radiometer (ASTER) images collected in February 2010.

\section{INSTRUMENTS, DATA AND METHODS}

In January 2010, a field campaign was conducted to Glaciar Jorge Montt, the main aims of which were to study the sedimentation rates near the glacier front, the long-term glacier variations, the oceanographic conditions at the new fjord opened by the glacier retreat and the ice velocities. This last topic of research is the main focus of this paper.

During the field visit, many icebergs and brash ice blocked most of the fjord, making it difficult to survey the 


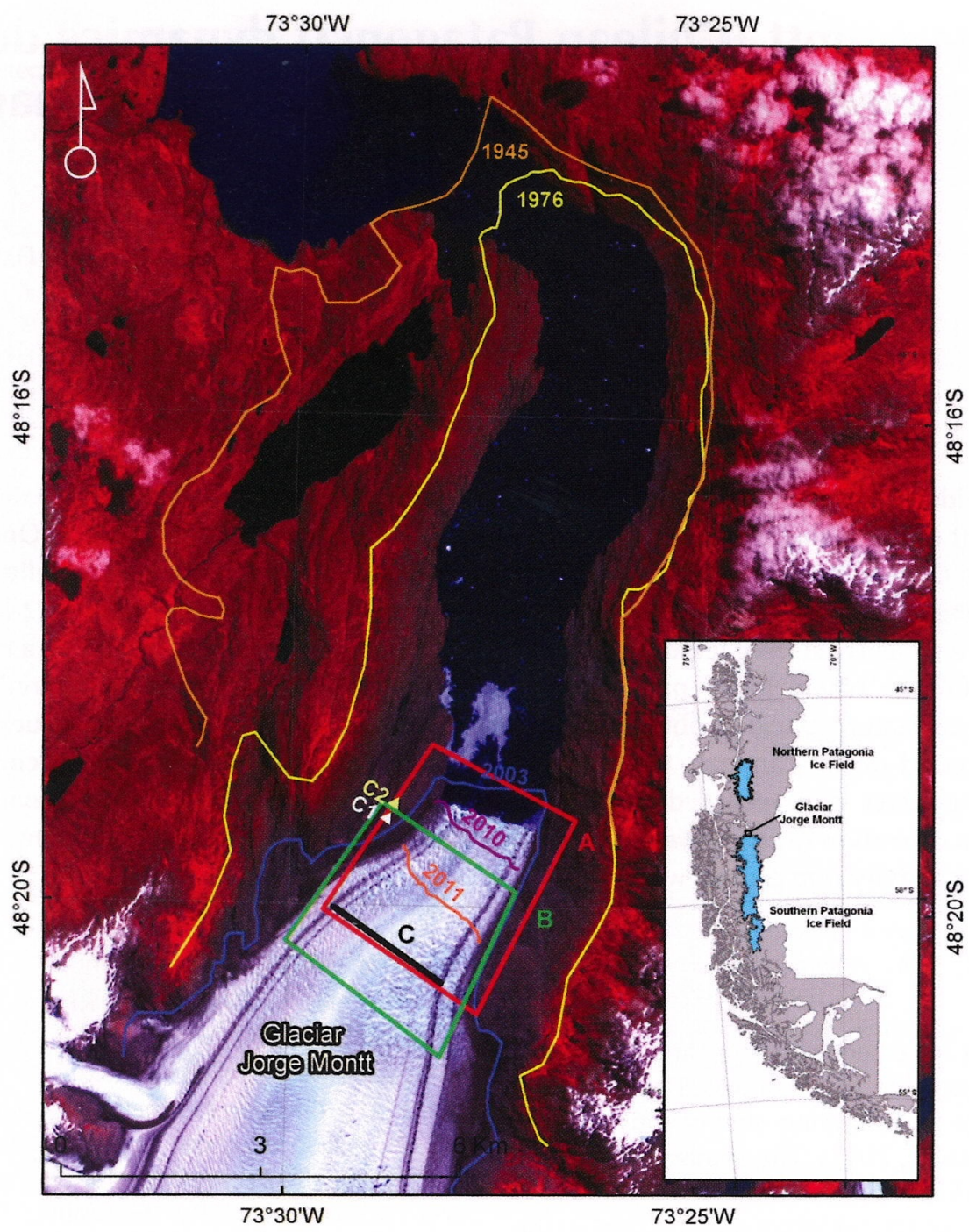

Fig. 1. Jorge Montt glacier frontal variations, 1945-2011. C1 and C2 are the locations of the fixed CANON cameras discussed in the text. The background is an ASTER image from 2008. The red box A indicates the area with ice velocities described in Figure 5 . The green box B is the area with ice velocities described in Figure 6 . The black line $\mathrm{C}$ is the location of the profile used for comparison purposes in Figure 7.

inner fjord. Despite these difficulties, a metal boat landed near the glacier front at its western margin allowed the glacier margin and other local features to be measured using JAVAD model Lexon GD dual-frequency GPS receivers. Two spots located $198 \mathrm{~m}$ apart were considered suitable for installing the photographic cameras, because they gave privileged views of the lower tongue of the glacier. These spots were drilled and a metal pin point was glued to the rock hole. The GPS receivers were installed on top of this metal pin for $30 \mathrm{~min}$ to give a position of $\sim 20 \mathrm{~cm}$ accuracy after PPS (Post Processing Software) post-processing (C1 and $\mathrm{C} 2$ in Fig. 1). Two metal boxes were installed and tied to the above-described metal points, in order to site the cameras (Fig. 2). Plastic suitcases containing the cameras were installed in the metal boxes.

Two digital CANON EOS Rebel xti 400D 10.1-megapixel cameras were used in the field, featuring a complementary metal oxide semiconductor (CMOS) sensor of $22.2 \mathrm{~mm}$ $\times 14.8 \mathrm{~mm}$ with an aspect ratio of $3: 2$ (horizontal/vertical), including EF-S lenses with focal distances of $18-55 \mathrm{~mm}$ and a maximum aperture of $1: 3.5-5.6$. The internal batteries of the cameras were supplemented by $12 \mathrm{~V} 40 \mathrm{Ah}$ batteries connected to electronic cards including a timer, able to ensure the cameras' operability until the data were recovered a year later. These cards were designed to regulate the voltage and activate the camera up to four times a day. They were made by two d.c-d.c. converter modules in cascade.

Camera C1, using a focal length of $25 \mathrm{~mm}$, successfully operated between 8 February and 30 October 2010, collecting four photos per day at 08:00, 12:00, 16:00 and 20:00 local time. Camera C2, using a focal length of $18 \mathrm{~mm}$, operated continuously between 8 February 2010 and 15 January 2011, collecting four photos per day. Cameras were triggered by an external timer and could not be synchronized.

\section{GLACIER SURFACE VELOCITIES FROM TERRESTRIAL CAMERAS}

\subsection{Camera orientation}

Only two well-measured ground-control points (GCPs) are visible from each camera, and at least three points are needed for space resection or exterior orientation of the image (Luhmann and others, 2006). In order to obtain the 


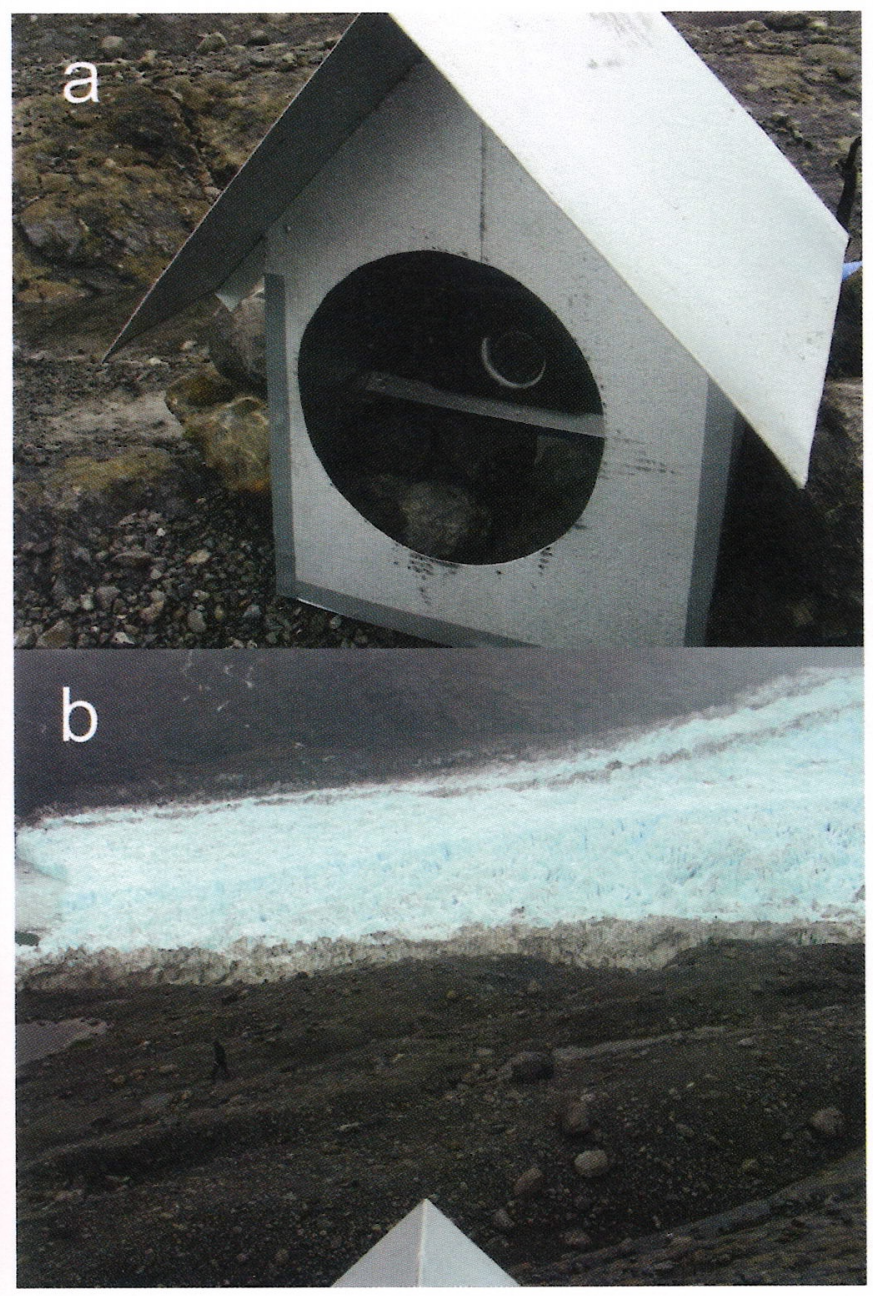

Fig. 2. (a) Camera set-up in the field and (b) the view from camera toward the glacier front. camera orientation with the available information, we used a DEM (digital elevation model, ASTERGDEM, $30 \mathrm{~m}$ resolution) and a procedure developed by Corripio (2004) for geo-referencing oblique images. This procedure establishes a mapping function between image space and object space by projecting the processed DEM to oblique image and adjusting camera attitudes for the best fit between two data in two-dimensional image space (Fig. 3). The procedure has been successfully applied to an ice-capped volcano in southern Chile (Rivera and others, 2008). Fine adjustments were made manually, by changing the viewing direction vector until the DEM matched the image, indicating that camera orientation was correct. This procedure identifies both the viewing direction and the roll of the camera, or rotation around the axis defined by the viewing direction vector $(\widehat{N}$ in the camera coordinate system). Once the orientation is known, the camera reference system is defined by the orthogonal vectors $\widehat{U}, \widehat{V}, \widehat{N}$ (Fig. 4).

\subsection{Feature tracking from stereo pair}

Two cameras were installed overlapping large sections of Glaciar Jorge Montt near the snout at a hill with a good view of the lower part of the glacier (Fig. 1). By precisely identifying the lines of sight from each camera with the same points on the ice, on nearly simultaneous $(<3$ min apart) images from both cameras, the approximate location of these points could be inferred. Using the same points on images at different times and on different days, their displacement and, therefore, surface ice velocities were calculated.

Although the cameras are not metric, distortion is not expected to be excessive, especially near the centre of the image. The analysis of defined geometrical structures and parallel lines photographed by the CANON 400D camera revealed a maximum barrel distortion of 24 pixels for a lens of $25 \mathrm{~mm}$ focal length near the corners of the image, and up

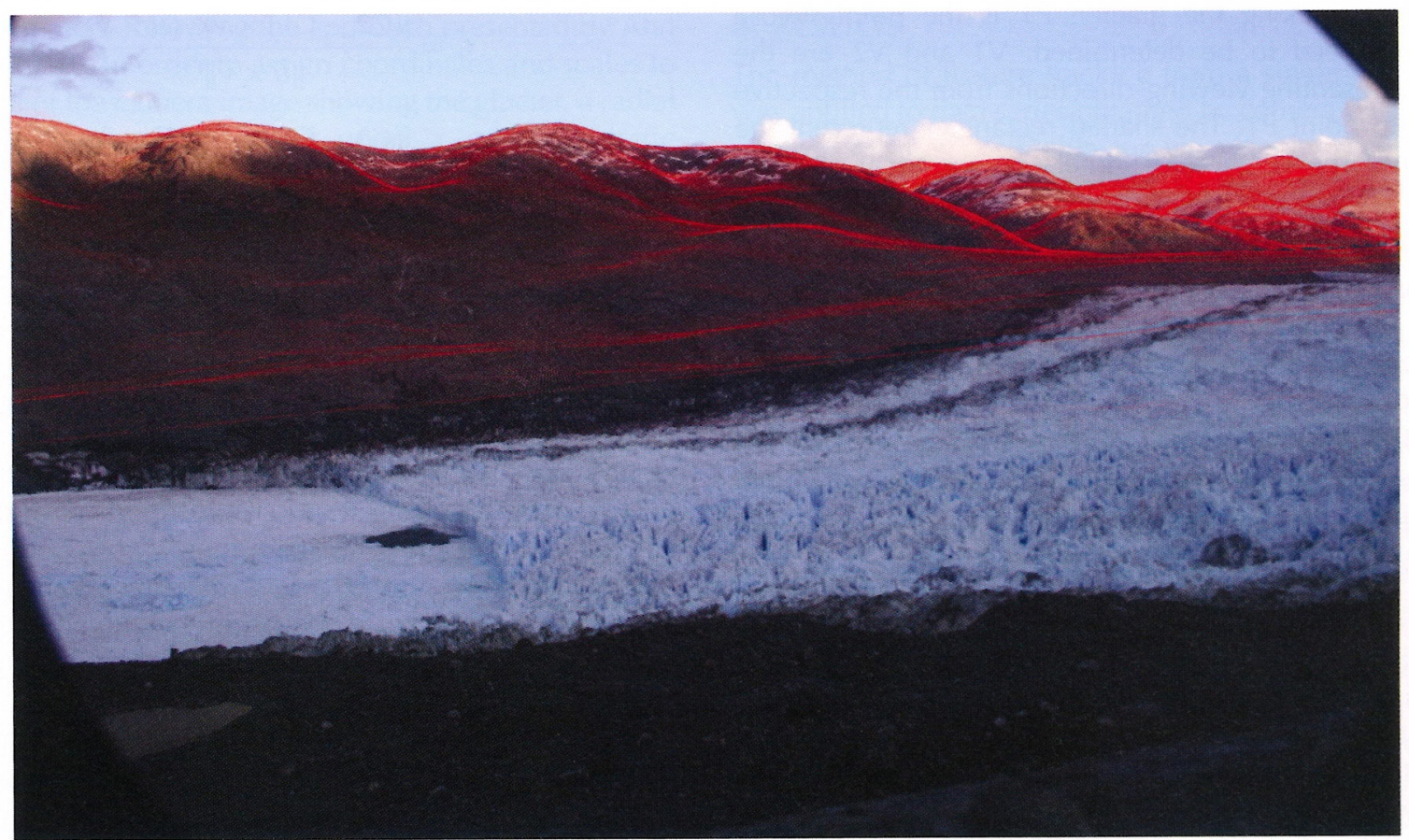

Fig. 3. Camera orientation determined by geo-referencing the photographs to a DEM (red lines) of the area. The black areas at the image corners are the shadows of the camera house. 


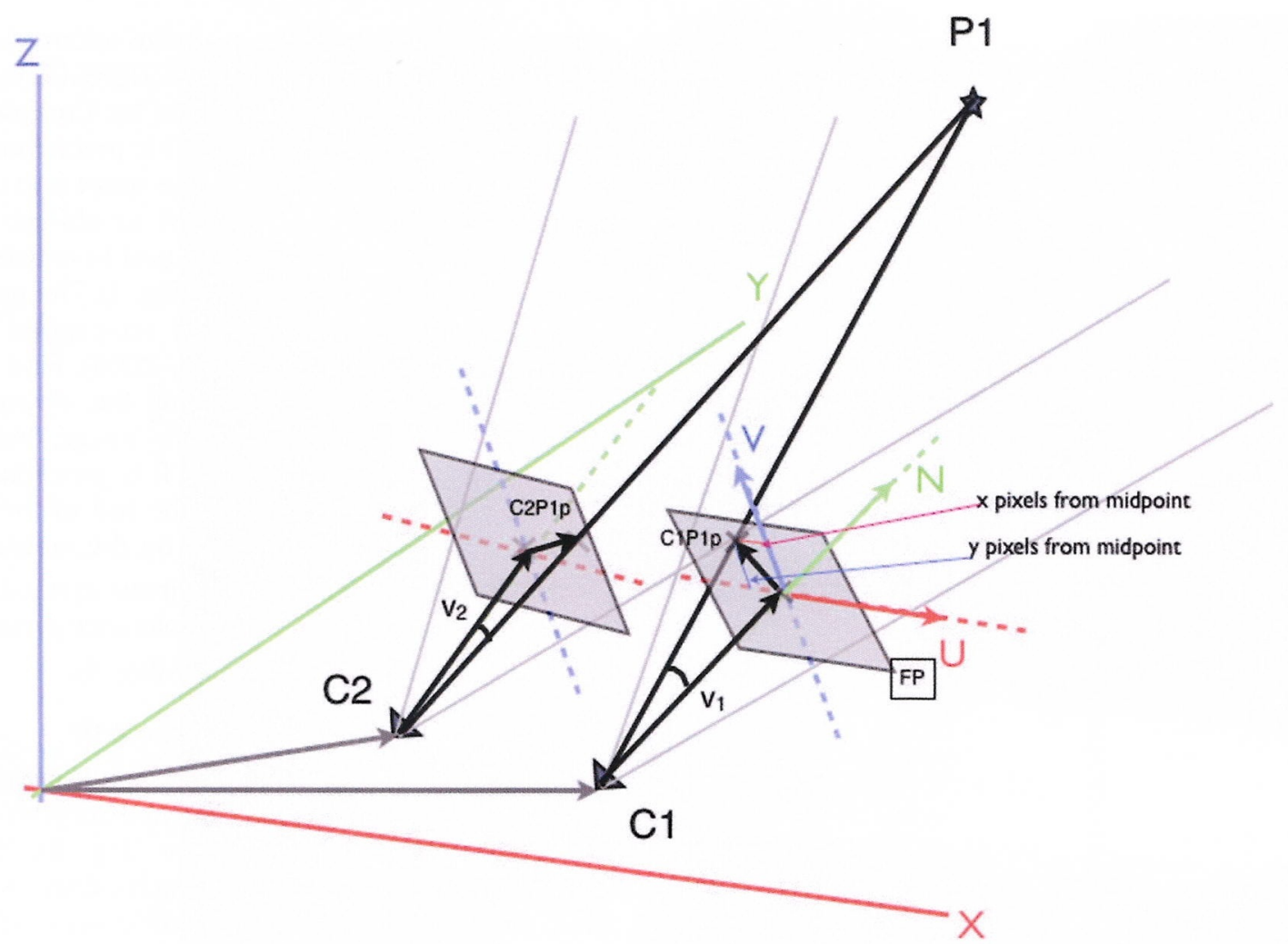

Fig. 4. Schematic representation of viewing geometry for both cameras (C1 and C2). The shaded rectangle is the focal plane (FP in box). P1 is the point whose coordinates need to be determined. The shaded rectangles represent the image projection. C1P1 $p$ represents the projection of point $\mathrm{P} 1$ on the photography from camera 1 ; this position is located at $y$ pixel points in the vertical from the centre of the image (blue thin line) and at $x$ pixel points in the horizontal from the midpoint of the image (red thin line, both labelled). Knowing the camera orientation, the lines $\mathrm{C} 1 \mathrm{P} 1 p$ and $\mathrm{C} 2 \mathrm{P} 1 p$ can be geometrically defined and the intersection, $\mathrm{P} 1$, estimated. $\widehat{U}, \widehat{V}, \widehat{N}$ are the vectors defining the camera coordinate system.

to 55 pixels for a lens of $18 \mathrm{~mm}$ focal length. This adds a potential error of up to $4 \mathrm{md}^{-1}$ to the calculated displacements.

Figure 4 shows the viewing geometry of both cameras (C1 and $\mathrm{C} 2$ ) overlooking the glacier. P1 is the point whose coordinates need to be determined. V1 and $\mathrm{V} 2$ are the vectors representing viewing directions from the respective cameras, to point $\mathrm{P} 1$. The shaded rectangles represent the focal plane. The vector C1P1 intersects the focal plane at point $\mathrm{C} 1 \mathrm{P} 1 p$, which is at $x, y$ pixels from the midpoint of the image (labelled in Fig. 4). The vector C1C $\overrightarrow{P P} 1 p$ can be defined as $\vec{N}+f_{x} \vec{U}+f_{y} \vec{V}$ where $f$ denotes the focal length (m), $f_{X}$ is the number of pixels in the $X$ direction times the pixel size and $f y$ is the number of pixels in the $Y$ direction times the pixel size. The pixel size is usually a few micrometres, varying for each camera type $(5.71 \mu \mathrm{m}$ in this case). Once the camera orientation is known, $\widehat{N}$ is defined, and $\widehat{U}$ and $\widehat{V}$ can be derived easily: $\vec{V}=\vec{N}_{x} \times \vec{N}$, where $\times$ denotes the cross product and $\vec{N}_{x}$ is the projection of $\widehat{N}$ on the $X Y$-plane or $\left(N_{x}, N_{y}=0\right) . \vec{V}$ would be $\vec{U} \times \vec{N}$ (Corripio, 2004). The vector in the direction of $\mathrm{C} 2 \mathrm{C} \overrightarrow{2} \mathrm{P} 1 p$ can be defined in a similar way.

Once these vectors are known and defined in the world coordinate system, the location of point P1 can be found as the intersection, or the point of minimum distance, between the lines defined as $\mathrm{C} 1+\lambda \widehat{u}$ and $\mathrm{C} 2+\lambda \widehat{v}$, where $\widehat{u}$ is the unit vector in the direction of $\mathrm{C} 1 \mathrm{C} \overrightarrow{\mathrm{P}} 1 p$ and $\widehat{v}$ is the unit vector in the direction of $\mathrm{C} 2 \mathrm{C} \overrightarrow{2} \mathrm{P} 1 p$.
Solving for

$$
\mathrm{C} 1+\lambda \widehat{u}=\mathrm{C} 2+\lambda \widehat{v}
$$

it is possible to obtain, following Dunn and Parberry (2002),

$$
\begin{gathered}
t_{1}=\frac{[(\mathrm{C} 2-\mathrm{C} 1) \times \widehat{v}] \cdot(\widehat{u} \times \widehat{v})}{\|\widehat{u} \times \widehat{v}\|^{2}} \\
t_{2}=\frac{[(\mathrm{C} 2-\mathrm{C} 1) \times \widehat{u}] \cdot(\widehat{u} \times \widehat{v})}{\|\widehat{u} \times \widehat{v}\|^{2}} \\
\mathrm{P} 1=\mathrm{C} 1+t_{1} \widehat{u} \\
\mathrm{P} 2=\mathrm{C} 2+t_{2} \widehat{v}
\end{gathered}
$$

P1 and P2 always produce different positions (space intersection) and it is conventional to compute the middle position using the average of Eqns (4) and (5) (Fig. 4).

\subsection{Feature tracking from single fixed camera}

To obtain ice velocities by this technique, camera $\mathrm{C} 1$ with a focal length of $25 \mathrm{~mm}$ was selected, because this focal length provided a better image resolution, and had smaller pixel deformation at the image corners. Considering the optical characteristics of this camera, the viewing angles are $47.88^{\circ}$ horizontal and $39.97^{\circ}$ vertical. Using these parameters, the individual angle per pixel of the image was determined by dividing the total camera angle by the number of pixels.

Apart from the two GCPs measured with GPS, the available ASTER scenes and corresponding DEMs acquired during the camera operation (specifically on 16 and 


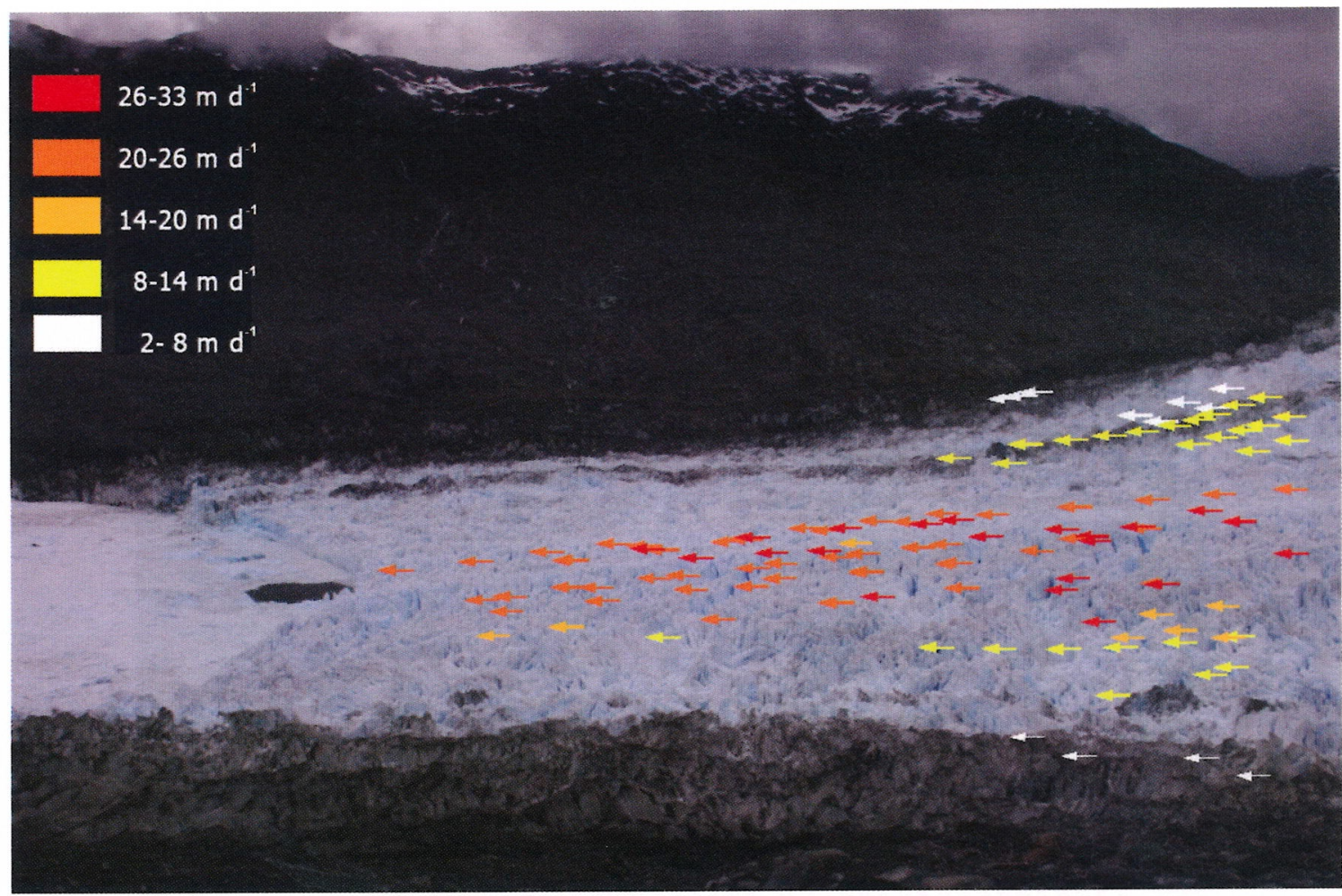

Fig. 5. Ice velocities obtained from camera C1 between February 2010 and October 2010.

25 February and 8 June 2010) were used to extract new GCPs distributed all along the camera viewing area. In total, 32 GCPs were obtained using this method, which were mainly distributed close to the glacier calving front and were easily distinguished with the cameras and satellite images.

The distances and angles between the camera and each GCP were determined using the procedure described in Section 3.2. Assigning each GCP to a pixel of the camera image, and considering the angle represented by each pixel of the camera, the scale of each pixel and its coordinates were determined, following the approach presented by Ahn and Box (2010). In order to assign coordinates and scales to every pixel of the camera image showing the glacier, a radial interpolation procedure based upon a multi-quadratic function was applied (Franke, 1982), assuming that the glacier at this location has a surface with a constant slope and the rock background is well represented by the available ASTERGDEM. This interpolation produced a matrix where each pixel has different spatial resolutions depending on its position in relation to the camera.

The pixels within the area of interest on the glacier were tracked within the available image dataset, defining a set of pixels with displacements associated with the ice movement. For this purpose a MATLAB program and an open physics library (OSP, Open Source Physics) were used. Given the image deformations due to camera distortion and the inaccuracies in the determination of the same spot in successive scenes (every 4 hours), the estimated error was $4 \mathrm{~m}$.

\subsection{Glacier surface velocity from satellite imagery}

During the operation period of the cameras, a few cloud-free ASTER satellite images were acquired from Glaciar Jorge Montt. Two of these images, collected on 16 and 25 February 2010, allowed ice velocities near the glacier front to be determined using a feature-tracking procedure. For this purpose, the co-registered images were processed using the IMCORR software provided by the US National Snow and Ice Data Center and based upon the image-to-image crosscorrelation method described by Scambos and others (1992). The errors associated with this procedure are mainly due to co-registration inaccuracies, especially detected in rock areas where the horizontal displacements must be close to zero but in some cases yielded a couple of pixels.

\section{RESULTS}

The method of feature tracking from a single fixed camera was applied to data series obtained by camera C1, using 598 photos considered suitable for ice velocity measurements (the others were snow-covered, cloudy, misty, etc.). With these photos, a comprehensive ice velocity field was mapped for the lower part of the ablation area (approximately the last $2.6 \mathrm{~km}$ ), assigning for each photo-point with useful data and fewer than two standard deviations a mean velocity value with all available data collected during the period (Fig. 5). Minimum ice velocities near the detection error $(4 \mathrm{~m})$ were detected close to the rock margins, where the ice is partially debris-covered. The areas between the central flowline and this slow-moving ice exhibited ice velocities of $8-13 \pm 4 \mathrm{md}^{-1}$. Higher velocities were observed closer to the centre of the glacier, with a mean of $23 \pm 4 \mathrm{md}^{-1}$, and a maximum of $33 \pm 4 \mathrm{md}^{-1}$ near the glacier front at the main flowline of the glacier. When these velocities were analysed over the study period, no trends were detected (no seasonality), but some oscillations were detected within one standard deviation of the mean value.

Applying the feature tracking from the stereo-pair technique to a series of 19 photographs over 8 days collected on Glaciar Jorge Montt resulted in ice velocities of $15 \pm 4 \mathrm{~m} \mathrm{~d}^{-1}$ for a moraine band located $300 \mathrm{~m}$ from the eastern rock 


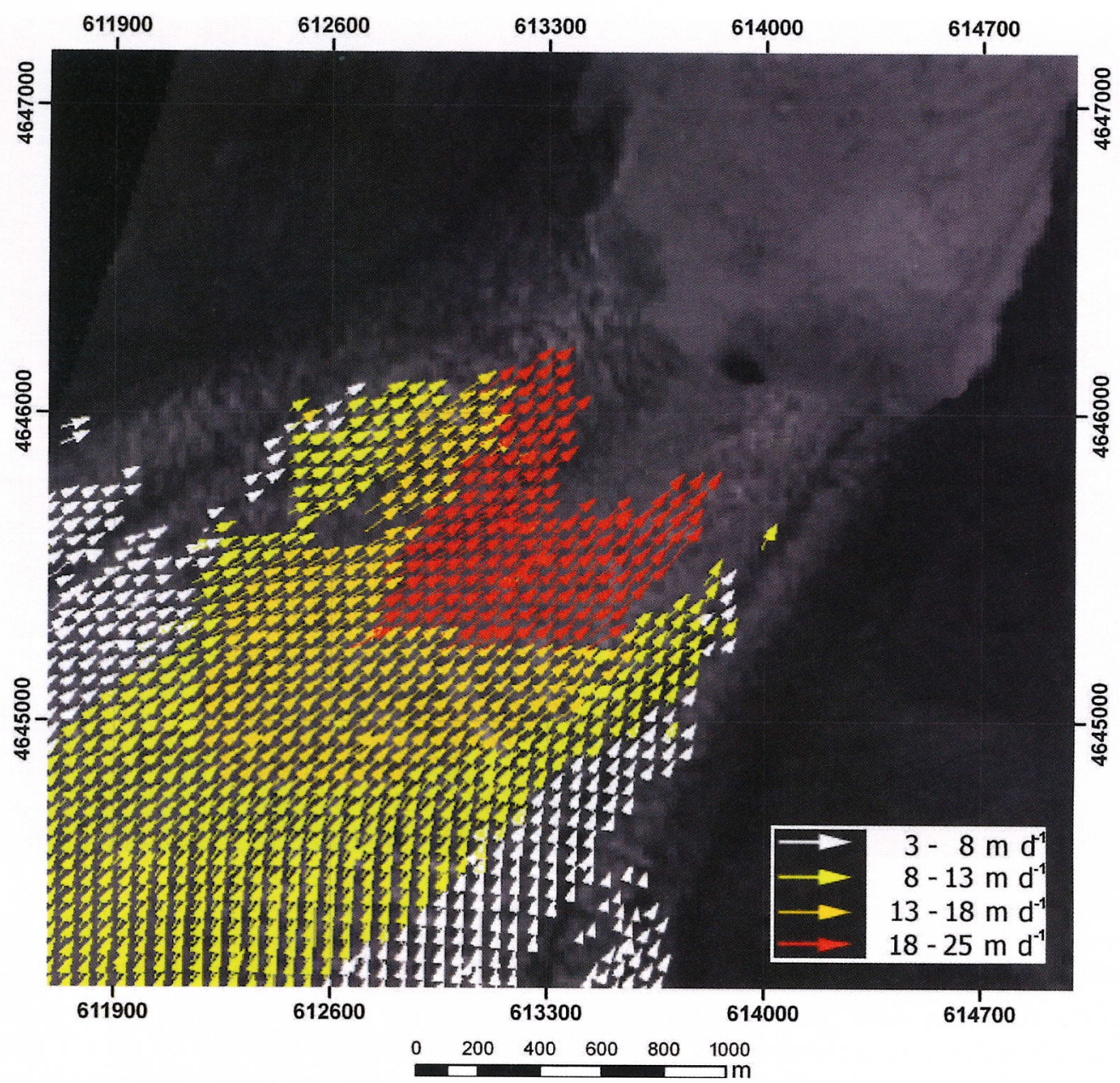

Fig. 6. Feature-tracking ice velocities derived from ASTER images collected on 16 and 25 February 2010. Background image from 16 February 2010 ( $3 \mathrm{~N}$ band). No ice velocities were obtained near the glacier front due to low coherence between the images. Coordinates are UTM-18S.

margin of the glacier, and $22 \pm 4 \mathrm{md}^{-1}$ for the central flowline of the glacier.

The satellite feature-tracking procedure based upon ASTER images from 16 and 25 February 2010 resulted in ice velocities between $3 \pm 2$ and $25 \pm 2 \mathrm{md}^{-1}$ (Fig. 6), the maximum values mainly located near the centre of the lower tongue. This procedure was successfully applied to an area located $\sim 1 \mathrm{~km}$ upstream of the glacier front, because the lower part near the ice front lost coherence during the 9 day period between the two dates of the ASTER scenes, due to much higher velocities. Otherwise, the values are higher near the central flowline and lower toward the margins and upstream of the glacier. The ice near the rock margins was poorly mapped compared to the centre of the glacier, due to very slow-moving ice; however, we detected some displacements higher than the estimated $2 \mathrm{~m}$ error.

\section{DISCUSSION}

The areas covered by the three procedures explained above are located in the ablation area near the glacier front, but do not completely coincide because the satellite featuretracking procedure lost coherence at this location, where the fixed cameras acquired more frequent photos, allowing the detection of higher velocities. In spite of this problem, all procedures yielded similar values, within the same range and distribution. The satellite feature tracking yielded relatively smaller values compared to the very high velocities detected by the fixed camera, especially when detecting movements near the glacier front. The stereoscopic capability using both cameras also yielded values similar to those given by the fixed camera, within one standard deviation. The $15 \pm 4 \mathrm{~m} \mathrm{~d}^{-1}$ at the lateral moraine measured with the stereoscopic method is within the range detected by the fixed camera (13-18 $\left.\pm 4 \mathrm{~m} \mathrm{~d}^{-1}\right)$.

This general agreement between the results obtained with the applied methods indicates that they are robust enough for mapping velocities and to be compared, with acceptable certainty, with previously obtained data.

Based upon speckle-tracking analysis of RADARSAT-1 images from September to November 2004, E. Rignot (personal communication, 2011) obtained a velocity map for the ablation area of Glaciar Jorge Montt, detecting a maximum of $10 \mathrm{~m} \mathrm{~d}^{-1}$ in an area located $\sim 3 \mathrm{~km}$ upstream of the glacier front. Comparing this to the velocities obtained by the satellite feature-tracking method based upon ASTER images from February 2010, ice acceleration in recent years was detected (Fig. 7). The comparison area changed between 2004 and 2010, because the glacier retreated $1 \mathrm{~km}$ between these two dates, and the ice thinned at high rates. However, there was no change in slope in the area in question, which remains $2 \mathrm{~km}$ away from the front, making the comparison possible. The difference in acquisition season for the two datasets (spring vs summer) does not significantly affect the 


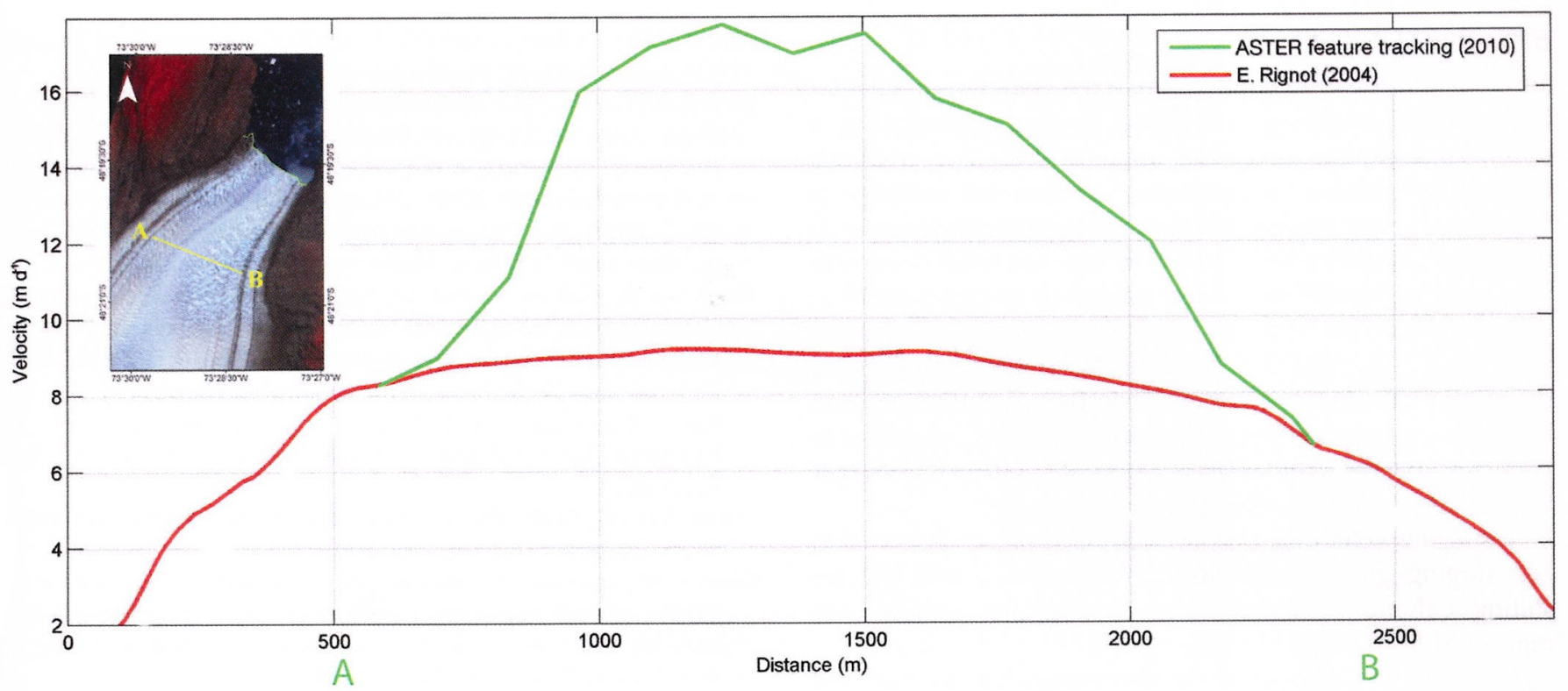

Fig. 7. Ice velocities comparison between E. Rignot data from RADARSAT-1 acquired in 2004 and the ASTER feature-tracking procedure obtained in 2010 along a transversal profile near the glacier front (A-B). The inset image is an ASTER scene from 16 February 2010.

resulting velocities, as the temperate conditions near the glacier front are similar in these months and no clear seasonality was detected during the study period.

In order to compare these results with previous calving flux data, the following boundary conditions for the last $2 \mathrm{~km}$ of the glacier before the calving front were considered:

elevation range $=0-200$ ma.s.l.,

water depth near the ice front, $w=400 \mathrm{~m}$,

cross-sectional bathymetry near the front, $\mathrm{LH}=0.32 \mathrm{~km}^{2}$

mean ice height above the sea, $h=75 \mathrm{~m}$,

ice surface slope, $\theta=6^{\circ}$,

measured surface ice velocities along the traverse profile, $V_{i},\left(\mathrm{~m} \mathrm{~d}^{-1}\right)$,

ice density, $\rho_{\mathrm{i}}=900 \mathrm{~kg} \mathrm{~m}^{-3}$,

sea-water density, $\rho_{\mathrm{s}}=1024 \mathrm{~kg} \mathrm{~m}^{-3}$,

frontal change during camera operation periods, $\mathrm{d} f=$ $-2.7 \mathrm{~m} \mathrm{~d}^{-1}$,

gravitational acceleration, $g=9.8 \mathrm{~m} \mathrm{~s}^{-2}$,

parameter 'A' (Cuffey and Paterson, 2010)

$=2.4 \times 10^{-24} \mathrm{~L}\left(\mathrm{~Pa}^{3} \mathrm{~s}\right)^{-1}$

Based upon the measured surface velocities and using the shallow-ice approximation (Cuffey and Paterson, 2010), the depth velocity, $U_{i}$, at the glacier front was calculated as

$$
U_{\mathrm{i}}=V_{\mathrm{i}}-0.1 A\left(\rho_{\mathrm{i}} g \sin \theta\right)^{3} H^{4}
$$

The calving velocity, $U_{\mathrm{c}}$, was then calculated based upon

$$
\mathrm{d} f=U_{\mathrm{i}}-U_{\mathrm{c}}
$$

and, finally, the calving flux, $c$, based upon

$$
c=U_{c} \mathrm{LH}
$$

The resulting mean surface velocity was $13 \mathrm{md}^{-1}$, the depth-averaged velocity was $12 \mathrm{~m} \mathrm{~d}^{-1}$ and the mean calving velocity was $25 \mathrm{~m} \mathrm{~d}^{-1}$. The total calving flux was $2.4 \mathrm{~km}^{3} \mathrm{a}^{-1}$.
This is much higher than calving fluxes obtained at any other glacier in Patagonia (Warren and Aniya, 1999). However, two assumptions used in previous studies add uncertainty: (1) the use of 'square' cross-sectional bathymetry due to lack of precise data near the ice front $(\mathrm{LH}$, based upon the glacier width times maximum water depth plus ice height); and (2) the use of a mean velocity based upon the higher detected values, normally obtained at the centre of the glacier, where it is easier to obtain significant results. In the present work, $\mathrm{LH}$ was calculated using all measured water depth data near the glacier front, and all measured ice velocities along the cross section near the glacier front were used, not only a single mean value.

These extreme results indicate a clear imbalance in Glaciar Jorge Montt, expressed as ongoing strong retreat, high thinning rates and high calving fluxes. These values need to be related to a dynamic response of the glacier to a deep fjord, especially when, following Naruse and Skvarca (2000), the height above buoyancy, or ice thickness in excess of flotation, $F$, defined as

$$
F=(h+w)-w \rho_{\mathrm{s}} / \rho_{\mathrm{i}}
$$

is applied to Jorge Montt data, resulting in values $20-30 \mathrm{~m}$ in excess of flotation near the glacier front. This implies a fragile equilibrium too close to buoyancy conditions, indicating that small changes induced by tides, high ablation or local dynamics could push the glacier near the front to float. This condition was neglected by Meier and Post (1987), who stated that no temperate tidewater glaciers have floating termini. At Glaciar Jorge Montt, however, floating conditions were clearly reached, especially when inspecting the movie produced by the fixed camera, showing large calving events, one of them producing an ice area reduction of $0.3 \mathrm{~km}^{2}$ that took place in February 2010, yielding tabular icebergs floating away from the calving front.

The recent behaviour of Glaciar Jorge Montt fits well with the retreating phase of the tidewater calving glacier cycle described by Post and others (2011), where retreats are rapid and catastrophic, as a result of coupled rates of ice flow (resupply) and calving. 


\section{CONCLUSIONS}

Three methods were applied to map ice velocities at Glaciar Jorge Montt, a tidewater calving glacier experiencing a continuous frontal recession since 1898. The methods applied enabled us to determine a mean ice velocity of $13 \pm 4 \mathrm{~m} \mathrm{~d}^{-1}$ at a transversal close to the glacier front, with minimum values of less than $4 \mathrm{~m}$ (the detection error) at the ice close to the rock sides, values of $8-13 \pm 4 \mathrm{~m} \mathrm{~d}^{-1}$ at the glacier centre margins and a maximum velocity of $33 \pm 4 \mathrm{~m} \mathrm{~d}^{-1}$ at the main flowline. Velocities were similar when all methods were spatially compared, and no seasonality was detected. However, when they were compared to previous ice velocities based upon RADARSAT-1 images from 2004, a clear acceleration was detected.

These ice velocities are among the highest observed in non-surging glacier behaviour in Patagonia, and the resulting calving fluxes are also among the highest ever registered in the region.

A modelling approach is recommended to test the possible consequences of this ice dynamic for the rest of the glacier, especially if the high velocities and calving fluxes at the glacier front are generating pulling stresses already spread upstream, reaching the local ice divide where even an ice-divide migration could be produced.

\section{ACKNOWLEDGEMENTS}

This research was funded by Fondecyt (Fondo Nacional de Ciencias y Tecnologia, Chile) 1080320. Allen Szydlowski (Waters of Patagonia) gave great logistic support. Bernard Hallet, Chuck Nittrouer, Katie Boldt, Michele Koppes, Dick Sylwester, Golder Associates Inc., Camilo Rada, Juan Andrés Uribe, David Farías, Francisco Sepúlveda, Daniela Carrión, Felipe Napoleoni and Marius Schaefer collaborated in this research. Eric Rignot provided the ice velocities obtained from RADARSAT-1 speckle-tracking procedures. Andrés Rivera is a Guggenheim fellow. Anonymous reviewers improved the manuscript. The Centro de Estudios Cientificas (CECS) is funded by the Chilean Government through the Millennium Science Initiative and the Centers of Excellence Base Financing Program of CONICYT.

\section{REFERENCES}

Ahn Y and Box JE (2010) Glacier velocities from time-lapse photos: technique development and first results from the Extreme Ice Survey (EIS) in Greenland. J. Glaciol., 56(198), 723-734 (doi: 10.3189/002214310793146313)

Aniya M, Sato H, Naruse R, Skvarca P and Casassa G (1996) The use of satellite and airborne imagery to inventory outlet glaciers of the Southern Patagonia Icefield, South America. Photogramm. Eng. Remote Sens., 62(12), 1361-1369

Aniya M, Sato H, Naruse R, Skvarca P and Casassa G (1997) Recent glacier variations in the Southern Patagonia Icefield, South America. Arct. Alp. Res., 29(1), 1-12

Ciappa A, Pietranera L and Battazza F (2010) Perito Moreno Glacier (Argentina) flow estimation by COSMO SkyMed sequence of high-resolution SAR-X imagery. Remote Sens. Environ., 114(9), 2088-2096 (doi: 10.1016/j.rse.2010.04.014)

Corripio J (2004) Snow surface albedo estimation using terrestrial photography. Int. J. Remote Sens., 25(24), 5705-5729 (doi: 10.1080/01431160410001709002)

Cuffey KM and Paterson WSB (2010) The physics of glaciers, 4th edn. Butterworth-Heinemann, Oxford
Dunn F and Parberry I (2002) 3D math primer for graphics and game development. Wordware, Sudbury, MA

Enomoto $\mathrm{H}$ and Abe $\mathrm{Y}$ (1983) Reconnaissance studies of meteorology and glaciology in Steffen and Jorge Montt glaciers, Patagonia. In Naruse R ed. Glaciological and meteorological studies in Patagonia, Chile, by Japanese research expeditions in 1967-1982. Data Center for Glacier Research, Japanese Society of Snow and Ice, Tokyo, 11-14

Floricioiu D, Eineder M, Rott H, Yague-Martinez N and Nagler T (2009) Surface velocity and variations of outlet glaciers of the Patagonia Icefields by means of TerraSAR-X. In IGARSS ' 09. International Geoscience Remote Sensing Symposium, 13-17 July 2009, Cape Town, South Africa. Proceedings, Vol. 2. Institute of Electrical and Electronic Engineers, Piscataway, NJ, 1028-1031

Franke R (1982) Scattered data interpolation: tests of some methods. Math. Comput., 38(157), 181-200

Glasser NF, Harrison S, Jansson KN, Anderson K and Cowley A (2011) Global sea-level contribution from the Patagonian Icefields since the Little Ice Age maximum. Nature Geosci., 4(5), 303-307 (doi: 10.1038/ngeo1122)

Hashimoto T and 10 others (2009) An introduction of high-precise 3D measurement system and its applications. JAMRIS, 3(4), 25-28

Hashimoto T and 8 others (2011) Applications of high-precise three-dimensional measurement system. Adv. Mater. Res., 222, 62-65 (doi: 10.4028/www.scientific.net/AMR.222.62)

Kadota T, Naruse R, Skvarca P and Aniya M (1992) Ice flow and surface lowering of Tyndall Glacier, southern Patagonia. Bull. Glacier Res., 10, 63-68

Kondo $\mathrm{H}$ and Yamada $\mathrm{T}$ (1988) Some remarks on the mass balance and the terminal-lateral fluctuations of San Rafael Glacier, the Northern Patagonia Icefield. Bull. Glacier Res., 6, 55-63

Luhmann T, Robson S, Kyle S and Harley I (2006) Close range photogrammetry: principles, methods and applications. Whittles, Dunbeath

Masiokas M, Rivera A, Espizua LE, Villalba R, Delgado S and Aravena JC (2009) Glacier fluctuations in extratropical South America during the past 1000 years. Palaeogeogr., Palaeoclimatol., Palaeoecol., 281(3-4), 242-268 (doi: 10.1016/j.palaeo.2009.08.006)

Meier MF and Post A (1987) Fast tidewater glaciers. J. Geophys. Res., 92(B9), 9051-9058

Naruse R (1985) Flow of Soler Glacier and San Rafael Glacier. In Nakajima C ed. Glaciological studies in Patagonia Northern Icefield, 1983-1984. Data Center for Glacier Research, Japanese Society of Snow and Ice, Nagoya, 64-69

Naruse R (1987) Characteristics of velocity distribution in Patagonian glaciers. Geophys. Bull. Hokkaido Univ., 49, 211-219 [In Japanese with English summary]

Naruse R and Skvarca P (2000) Dynamic features of thinning and retreating Glaciar Upsala, a lacustrine calving glacier in southern Patagonia. Arct. Antarct. Alp. Res., 32(4), 485-491

Post A, O'Neel S, Motyka RJ and Streveler G (2011) A complex relationship between calving glaciers and climate. Eos, 97(37), 305-306 (doi: 10.1029/2011EO370001)

Rignot E, Forster R and Isacks B (1996a) Interferometric radar observations of Glaciar San Rafael, Chile. J. Glaciol., 42(141), 279-291

Rignot E, Forster R and Isacks B (1996b) Mapping of glacial motion and surface topography of Hielo Patagónico Norte, Chile, using satellite SAR L-band interferometry data. Ann. Glaciol., 23, 209-216

Rignot E, Rivera A and Casassa G (2003) Contribution of the Patagonian icefields of South America to sea level rise. Science, 302(5644), 434-437

Rivera A, Lange H, Aravena JC and Casassa G (1997) The 20thcentury advance of Glaciar Pio XI, Chilean Patagonia. Ann. Glaciol., 24, 66-71 
Rivera A, Corripio JG, Brock B, Clavero J and Wendt J (2008) Monitoring ice-capped active Volcán Villarrica, southern Chile, using terrestrial photography combined with automatic weather stations and global positioning systems. J. Glaciol., 54(188), 920-930 (doi: 10.3189/002214308787780076)

Scambos TA, Dutkiewicz MJ, Wilson JC and Bindschadler RA (1992) Application of image cross-correlation to the measurement of glacier velocity using satellite image data. Remote Sens. Environ., 42(3), 177-186

Steffen H (1910) Viajes de esploracion $i$ estudio en la Patagonia Occidental, 1892-1902. Anexo de los anales de la Universidad de Chile, Santiago
Stuefer M, Rott H and Skvarca P (2007) Glaciar Perito Moreno, Patagonia: climate sensitivities and glacier characteristics preceding the 2003/04 and 2005/06 damming events. J. Glaciol., 53(180), 3-16 (doi: 10.3189/172756507781833848)

Sugiyama $S$ and 7 others (2011) Ice speed of a calving glacier modulated by small fluctuations in basal water pressure. Nature Geosci., 4(9), 597-600 (doi: 10.1038/ngeo1218)

Warren C and Aniya M (1999) The calving glaciers of southern South America. Global Planet. Change, 22(1-4), 59-77

Warren CR, Glasser NF, Harrison S, Winchester V, Kerr AR and Rivera A (1995) Characteristics of tide-water calving at Glaciar San Rafael, Chile. J. Glaciol., 41(138), 273-289 